\title{
Changes in neonatal mortality and newborn health- care practices: descriptive data from the Bangladesh Demographic and Health Surveys 2011 and 2014
}

Tasnima Akter, Angela Dawson, David Sibbritt

Faculty of Health, University of Technology, Sydney, Australia

Correspondence to: Ms Tasnima Akter (tasnima akter@yahoo.com)

\begin{abstract}
Background Bangladesh has made major improvements in health outcomes over the past two decades, with falls in mortality rates in mothers and in infants and young children aged under 5 years. Despite these improvements, neonatal mortality rates (NMRs) are high in Bangladesh. This paper describes recent changes in NMRs and health-care practices, disaggregated by demographic and socioeconomic characteristics.

Methods Summary statistics from the reports of the Bangladesh Demographic and Health Survey (BDHS) were examined. The BDHS is a nationally representative cross-sectional survey and the two most recent rounds of surveys, 2007-2011 and 2010-2014, were included in the analysis. The variables considered in this study were neonatal deaths and related health-care practices, including antenatal care visits, facility-based delivery, assistance from a medically trained provider during delivery, postnatal care from a trained provider and essential newborn care.

Results Between the two survey periods, NMRs increased in Chittagong (average increase $4.5 \%$ per year) and Khulna (8.3\% per year), remained unchanged in Rangpur, and decreased in Barisal (average decrease $19.8 \%$ per year), Dhaka (12.2\% per year), Rajshahi (7.7\% per year) and Sylhet (4.8\% per year). A larger average annual reduction in the NMR was observed in urban areas than in rural areas (14.0\% versus $2.1 \%)$. There was also a large average reduction in NMR in the fourth and fifth richest quintiles for socioeconomic status (SES quintiles; $12.0 \%$ and $16.5 \%$ per year, respectively). Differences according to neonatal sex were also noted: the NMR for female neonates remained unchanged and that for male neonates reduced by an annual average of $7.7 \%$. General improvements were observed in all health-care practices across all demographic and socioeconomic groups. However, the urban-rural gap in the uptake of antenatal care services, facility-based delivery, assistance from a medically trained provider during delivery, and postnatal care from a trained provider was roughly similar in both surveys. A similar unchanging gap was also seen between the poorest and richest SES quintiles.

Conclusion The study analysis indicates that improvements in NMRs between the two survey periods are mixed. Further attention is required to improve the rate of reduction of neonatal mortality in some divisions in Bangladesh, and it may be useful to investigate whether the higher
\end{abstract}


NMR in rural areas and for households with lower socioeconomic status can be reduced by strengthening the uptake of antenatal care services, facility-based delivery, assistance from a medically trained provider during delivery, and postnatal care from a trained provider. The static NMR for female neonates may encourage policy-makers to focus on ensuring standard essential newborn care practices for both sexes and ensuring adequate and appropriate care-seeking for illness in female neonates.

Keywords: antenatal care, Bangladesh, essential newborn care, facility-based delivery, health-care practices, neonatal mortality, postnatal care

\section{Background}

Bangladesh is the eighth most populous country in the world, with a density of 1070 persons $/ \mathrm{km}^{2}{ }^{1,2}$ Over the last 47 years since independence in 1971, the country has developed an extensive health infrastructure and made remarkable progress in providing important health-care and service inputs. These include antenatal care services, delivery in a health facility, assistance from a medically trained provider during delivery, childhood immunization, vitamin A supplementation, uptake of oral rehydration therapy for diarrhoea, and treatment success rates for tuberculosis. ${ }^{1,3}$ For example, between 1996-1997 and 2016, antenatal care from a medically trained provider and assistance from a medically trained provider during delivery increased from $26 \%$ to $64 \%$ and $8 \%$ to $42 \%$, respectively. ${ }^{2,4}$ These improvements may be attributed to the way Bangladesh has managed to deliver health services, specifically its widespread deployment of community-based strategies to serve every household in the country. ${ }^{1,3,5}$

Improvements in health-care and service inputs have been translated into exceptional achievements across different health outcomes in Bangladesh. The total fertility rate has decreased from 6.3 births per women in 1975 to 2.3 births per woman in 2014, while between 2001 and 2016 the maternal mortality ratio declined from 322 to 196 per 100000 live births. ${ }^{6,7}$ Bangladesh has also made important progress in child survival over the last two decades. Between 1989-1993 and 2010-2014, the mortality rate in children aged under 5 years declined from 133 to 46 per 1000 live births. ${ }^{2}$ Improvements in health-care services, together with community-based initiatives to tackle the demand-side of service use and other secular trends beyond the health sector, assisted Bangladesh to achieve the target of Millennium Development Goal 4 of an under-5 mortality rate of 48 per 1000 live births. ${ }^{2,3}$

Despite the considerable improvement in health outcomes in Bangladesh, the achievement remains vulnerable. For example, the risk of dying in the first month of life, which accounts for $61 \%$ of all deaths in children aged under 5 years, is still high (28 deaths per 1000 live births in 2014). ${ }^{2}$ This may be related to the scarcity of skilled health personnel- Bangladeshis included in a list of 57 countries facing a critical shortage of human resources for health. ${ }^{6,8}$ The situation is further aggravated by the disproportionate distribution of human resources for health between rural and urban areas and skewing towards physicians. In 2007, the ratio of physicians to nurses in urban areas was 1:0.3 and 1:0.7 in rural areas. ${ }^{9}$ Such barriers may affect the country's ability to maintain momentum and achieve the target of Sustainable Development Goal (SDG) 3 of reducing the neonatal mortality rate (NMR) to 12 per 1000 live births and under-5 mortality to 25 per 1000 live births by $2030 .{ }^{10}$ 
In this context, it may be helpful to look beyond aggregated data to examine recent changes and differences in NMRs and the uptake of related health-care practices among the socioeconomic groups in Bangladesh. This study therefore aims to examine recent changes in NMRs alongside health-care practices in the country, by demographic and socioeconomic characteristics.

\section{Methods}

\section{Data source}

Summary data from the Bangladesh Demographic and Health Survey (BDHS) 2011 and 2014 survey reports were used for this research. The BDHS is a cross-sectional survey and collects nationally representative demographic and health information every 3-4 years. ${ }^{2}$ This study compared data from the latest two BDHS reports, 2011 and 2014. ${ }^{2,11}$ The reference periods for these surveys were 2007-2011 for the BDHS 2011 and 2010-2014 for the BDHS 2014. The surveys involved two-stage stratified random sampling and collected information by interviewing ever-married men (aged 1554 years) and ever-married women of reproductive age (15-49 years). The sampling approach aimed to produce data that were representative for the country as a whole, for urban and rural areas separately, and for each of the seven administrative divisions. ${ }^{2,11}$ All survey information was selfreported and was gathered using separate questionnaires for households, women and the community. An additional questionnaire for men was used for the 2011 round only. The design and data-collection procedures are described in detail elsewhere. ${ }^{2,11}$

\section{Ethical approval}

The ICF Institutional Review Board approves demographic and health surveys, ${ }^{12}$ and informed consent was obtained from participants at the time of the interviews conducted for the original surveys. This research involves human participants but is based on secondary data analyses and so no further consent was required. This study was also approved by the Human Research Ethics Committee of the University of Technology, Sydney, Australia.

\section{Study participants}

This analysis relied on statistics for live-born infants in the BDHS 2011 and 2014. The analysis was restricted to the most recent births in the last 3 years preceding the survey, as detailed information on perinatal health-care practice was available only for these births. Information on essential newborn care services was available for home births only. Mothers were the respondents for information collected on essential newborn care and health-care practices.

\section{Neonatal mortality}

The BDHS studies defined neonatal mortality as death of a baby within the first month of life. ${ }^{2,11}$ The standard definition of neonatal mortality, as employed by the World Health Organization (WHO) and United Nations Children's Fund (UNICEF), is deaths occurring within the first 28 days of life. ${ }^{13}$ As a result, the BDHS definition may show slightly higher NMRs compared with the standard definition. Neonatal deaths were determined from the complete birth history from mothers, which included information on the baby's sex, date of birth, survival status (alive/dead) and age at death (if dead). Methodology used to estimate NMRs in the BDHS relied on life-table approaches that estimated age-specific person-time and deaths in each estimation year. ${ }^{2,11,14}$ 


\section{Health-care practices}

Previous research and the recommendations of WHO, UNICEF and the Government of Bangladesh were followed in selecting the health-care practices relevant to NMR. ${ }^{15-17}$ These practices included whether women received at least four antenatal care visits during the pregnancy preceding the most recent birth before the survey; whether delivery was at a health facility; whether there was assistance during delivery from a medically trained provider (defined as a qualified doctor, nurse, midwife, paramedic, family-welfare visitor or community skilled birth assistant); and whether postnatal check-ups were with a trained provider (which, in addition to the previous list, included medical assistants and sub-assistant community medical officers) and occurred within 2 days after birth. ${ }^{2,11}$ Four individual components of essential newborn care were also included in the list of health-care practices - the use of sterile/boiled instruments for cutting the umbilical cord; drying of the neonate after birth; delayed bathing (bathing the neonate at least $72 \mathrm{~h}$ after birth); and the initiation of breastfeeding within $1 \mathrm{~h}$ after delivery. ${ }^{15,18}$ The surveys collected information on the use of sterile/boiled instruments in binary form (yes, no), while the data on the timing of drying after birth were recorded as 0-4 min, 5-9 min, 10+ min or not dried; the category 0-4 min was used in this analysis. The data related to delayed bathing and immediate initiation of breastfeeding were collected as continuous variables. Two other recommended essential newborn care practices, umbilical cord care and immediate wrapping of neonate, were not included in the study analysis, as the related government guideline had been changed after 2011. ${ }^{2,15}$

\section{Demographic and socioeconomic variables}

Data on NMRs and related health-care practices were extracted for selected demographic and socioeconomic groups, including sex of the child, administrative division, urban/rural location, usual place of residence, and socioeconomic status of the participant. At the time of the two surveys, there were seven administrative divisions in Bangladesh: Barisal, Chittagong, Dhaka, Khulna, Rajshahi, Rangpur and Sylhet. ${ }^{2,11}$ The quintiles for socioeconomic status (SES quintiles) in the BDHS data were created using household asset information and principal components analysis; the methods are described elsewhere. ${ }^{2,11,19}$ The annual average rate of change by demographic and socioeconomic characteristics for the 3 years between the two BDHS surveys was calculated as the mean exponential growth rate. ${ }^{20}$

\section{Results}

The BDHS 2011 collected information from 17141 households, with an individual interview of 17842 ever-married women aged 15-49 years and a response rate of $98 \%$.The distribution of women respondents among divisions was $6 \%, 18 \%, 32 \%, 12 \%, 15 \%, 12 \%$ and $5 \%$ for Barisal, Chittagong, Dhaka, Khulna, Rajshahi, Rangpur and Sylhet, respectively. The majority of women (74\%) were residing in rural areas and $28 \%$ of women had received no education. The BDHS 2014 collected information from 17300 households, with an individual interview of 17863 ever-married women aged 15-49 years and a response rate of $98 \%$. The distribution of women respondents across divisions was similar to the previous round of the survey. In the BDHS 2014, 72\% of women respondents were from rural areas and around $25 \%$ of women had no education.

The NMR in Bangladesh was 32 per 1000 live births in the 2011 round of the survey and 28 per 1000 live births in the 2014 round. Thus, the NMR in the country had declined, with an annual average rate of reduction of $4.5 \%$ between the two survey periods (see Table 1 ). A comparison of NMRs 
among divisions indicated a decreasing mortality rate for Barisal, Dhaka, Rajshahi and Sylhet, with an annual average rate of reduction of $19.8 \%, 12.2 \%, 7.7 \%$ and $4.8 \%$, respectively. While the mortality rate remained unchanged in Rangpur, it increased in Chittagong and Khulna by $4.5 \%$ and $8.3 \%$ per year, respectively. A larger average annual reduction in the NMR was observed in urban areas than in rural areas (14.0\% versus $2.1 \%$ per year). A considerable difference in the reduction of NMRs was also observed among neonates of mothers with different socioeconomic status, with a large reduction seen in the fourth and fifth richest SES quintiles (12.0\% and $16.5 \%$ per year, respectively). Finally, the gap in NMR between male and female neonates narrowed between the two survey periods. However, the NMR reduced by $7.7 \%$ for male neonates, while that for female neonates remained unchanged.

Data on neonatal health-care practices by division are presented in Table 2. Three practices -facilitybased delivery, assistance from a medically trained provider at delivery, and drying within 4 min of birth - were improved in the BDHS 2014 compared with the BDHS 2011 in all divisions.

Improvements in receiving at least four antenatal care visits, as well as delayed bathing of neonates, was observed in all divisions except Barisal. No improvement in the use of sterile/boiled instruments for cutting the umbilical cord was observed in Barisal, Rajshahi, Rangpur or Sylhet. Initiation of breastfeeding within $1 \mathrm{~h}$ after delivery improved in all divisions except Chittagong.

An examination of the rural-urban dimension in the use of selected health-care practices for neonates indicated an improvement in all components except the use of sterile/boiled instruments for cutting the umbilical cord (see Table 3). There was only a minor rural-urban gap in the use of health-care practices related to essential newborn care, in either 2011 or 2014. However, the lower use of other selected health-care services in rural areas - receipt of at least four antenatal care visits, facility-based delivery, assistance from a medically trained provider during delivery, and postnatal care services from a trained provider - remained roughly constant between the two surveys.

Table 4 compares the changes in neonatal health-care practices by socioeconomic status. Except for the use of sterile/boiled instruments for cutting the umbilical cord, all selected practices improved between the BDHS 2011 and BDHS 2014 across all SES quintiles. However, a major gap between the poorest and the richest quintiles in the use of antenatal care, facility-based delivery, assistance from a medically trained provider at delivery, and postnatal care services from a trained provider were evident in both 2011 and 2014.

Table 5 presents data on selected neonatal health-care practice by sex. Between the 2011 and 2014 surveys, improvements were observed for all practices for both male and female neonates.

\section{Discussion}

This study examined the changes over time in NMRs and health-care practices by demographic and socioeconomic groups between the 2011 and 2014 rounds of BDHS data. No reduction of NMR was observed for three divisions - Chittagong, Khulna and Rangpur. A minimal decline of NMR was observed for rural areas, with a large improvement in the two richest SES quintiles; no reduction in NMR was found for female neonates. Conversely, improvements were largely seen in health-care practices across all divisions. Improvements in all health-care services, except essential newborn care, were also observed in both urban and rural areas, while the urban-rural gap in the uptake of 
these services remained roughly similar over time. A similar situation was found across the SES quintiles. Considerable progress in all types of practice was observed for both sexes.

\section{Neonatal mortality rate and health-care practices by division}

An unchanged NMR was observed in Rangpur and an increased NMR in Chittagong and Khulna, despite an improvement over time in the uptake of different neonatal health-care practices. The highest poverty rate in Bangladesh is observed in Rangpur, where famine-like situations (monga) are regularly experienced by the population. ${ }^{21,22}$ Research has also found an association between famine and child mortality. ${ }^{23}$ These may have contributed to the unchanged NMR in Rangpur. ${ }^{21,24} \mathrm{~A}$ similar argument can be made for Chittagong, which is particularly vulnerable to cyclones because of its location and proximity to the Bay of Bengal. ${ }^{25}$ For example, Bangladesh experienced a severe cyclone in May 2013, when 1.1 million people were evacuated from the coastal area. ${ }^{26}$ The geographical remoteness of Chittagong Hill Tracts, which is included in the Chittagong division, may also explain the increased NMR observed. Khulna, another division that has not experienced any improvement in mortality rate, has a poor connectivity with the capital city and other major centres and, as a coastal region, is vulnerable to cyclones that may affect the NMR in the division. ${ }^{2,11,27}$ Previous studies have also observed impacts of natural disasters on child health. ${ }^{28}$ However, a more detailed investigation is required to identify why improvement in NMRs varies across divisions in Bangladesh.

\section{Neonatal mortality rate and health-care practices by urban/rural areas}

High-quality health care during pregnancy, delivered under the supervision of health professionals, is required to reduce the risk of complications and infections that can cause neonatal deaths. Postnatal check-ups are also essential for monitoring neonatal complications, especially during the first 2 days after delivery, when a large proportion of neonatal deaths occur from sepsis, birth asphyxia and low birth weight/prematurity. ${ }^{29,}{ }^{30}$ The Bangladesh Government aimed to increase the proportion of pregnant women receiving at least four antenatal care visits, skilled assistance during delivery and neonates receiving at least one postnatal check-up to $50 \%$ by $2016 .{ }^{31}$ However, participants in both surveys from rural areas were receiving nearly half of the targeted services. Thus, a lower rate of uptake of antenatal care, facility-based delivery, assistance from a medically trained provider at delivery, and postnatal care from a trained provider may explain the lower reduction in NMR over time in rural areas, compared with the urban areas. Nevertheless, a higher NMR may be related to a weak health system, including shortage of skilled health workers in rural areas. ${ }^{32}$ With respect to potential interventions, a systematic review and meta-analysis found that the use of women's groups practising participatory learning and action was a cost-effective strategy to improve maternal and neonatal survival in low-resource settings. ${ }^{33}$

\section{Neonatal mortality rate and health-care practices by socioeconomic status}

The sustained reduction in the NMR in Bangladesh has not occurred equitably, as can be seen by the differences across various socioeconomic groups. Like the rural versus urban case, the use of antenatal care services, facility-based delivery, assistance from a medically trained provider at delivery, and postnatal care from a trained provider were also observed to improve least for the poorest three quintiles. An important point in this connection is that the majority of the rural population exists in the bottom three SES quintiles, with only $9 \%$ in the highest wealth quintile. ${ }^{2}$ The ratio of delivery in a health facility between women in the lowest and the highest quintiles was 1:6 in 
the 2011 which slightly improved to 1:5 in 2014 . The reduction in this ratio did not reach the government target of 1:4 by 2016 . $^{2,31}$

\section{Neonatal mortality rate and health-care practices by neonates' sex}

This study found a reduction in NMR for male neonates between the BDHS 2011 and BDHS 2014 but not for female neonates, despite considerable improvements in selected health-care practices. This may point towards a strong preference for male offspring, which is particularly common in South Asia and may influence women/carers care of a girl child. ${ }^{2}$ This is in line with some previous studies that have observed gender biases in neonatal care or for seeking health care in sickness, in favour of male infants. ${ }^{34}$

\section{Overall challenges in the health system in Bangladesh}

The density, skill mix and distribution of health professionals are closely associated with neonatal survival. ${ }^{8,35}$ Although the availability of health workers is increasing over time in Bangladesh, the density (per 10000 population) of physicians and nurses in the country in 2014 was 3.8 and 1.2 respectively. ${ }^{36}$ The health workforce is skewed towards doctors with a ratio of doctors to nurses of 1:0.4, compared with the WHO-recommended ratio of $1: 3 .^{6}$

The inequitable distribution of the health workforce is another challenge in Bangladesh. One study observed a substantial variation in the ratios of physicians to nurses in 2007 among the divisions Barisal (1:0.5), Chittagong (1:0.7), Dhaka (1:0.2), Khulna (1:1.4), Rajshahi (1:0.5) and Sylhet (1:0.1). ${ }^{9}$ Note that Rangpur was part of Rajshahi at the time the study was conducted. In addition, although $70 \%$ of the population of Bangladesh lives in rural areas, the health workforce is mainly concentrated in urban areas. This may result in rural facilities becoming overburdened and insufficiently equipped to deal with demand. ${ }^{6,9}$ Thus, not only the shortage of health workers but also the inappropriate skill mix and inequitable distribution of human resources for health in Bangladesh could be a major factor impeding the improvement of health outcomes, including neonatal mortality.

\section{Limitations of this study}

The present study cannot draw conclusions about the impact of health-care practices as well as demographic and socioeconomic variables on NMRs. However, the data presented are a useful starting point for further in-depth research on NMRs to achieve SDG 3 in Bangladesh. ${ }^{10}$ It is important to note that previous studies have also attempted to carry out a similar investigation of achievement of health-related goals. ${ }^{30}$ Also, the survey relies on self-reported information in which recall bias can be an important issue, as interviewees are required to recollect events as far back as 3 years. This may affect the responses of some demographic and socioeconomic groups differently and, consequently, responses for some groups may be more imprecise than for others. Furthermore, the surveys excluded women who died before the survey and so data relating to their birth practices are missing; data on essential newborn care and neonatal survival for these women could be systematically different from those for women who survived and were therefore included in the surveys. In addition, it was not possible in this study to provide comprehensive information, as detailed statistics were unavailable in the BDHS reports. Importantly, the BDHS 2014 notes that the findings for the selected socioeconomic and demographic differentials must be interpreted with caution, given the low precision of mortality estimates due to sampling error. ${ }^{2}$ 


\section{Conclusion}

This study on differences between the BDHS 2011 and BDHS 2014 in NMRs and health-care practices across selected demographic and socioeconomic groups is a useful starting point for further in-depth research. The study analysis found three main issues that need to be investigated further to inform policy and programmes in Bangladesh. First, the analysis indicates that it can be useful to investigate whether the higher NMRs in rural areas and for households with lower socioeconomic status can be reduced by emphasizing the importance of uptake of antenatal care services, facility-based delivery, assistance from a medically trained provider during delivery, and postnatal care from a trained provider. Second, the findings of an unchanged NMR in female neonates may encourage policymakers to focus on ensuring standard essential newborn care practices for both male and female neonates and ensuring adequate and appropriate care-seeking for illness for female neonates. Finally, no observed improvement in the NMR in some selected divisions may indicate that NMRrelated programmes in these areas need to be given special attention. Such measures would also be useful for improving NMRs in low- and middle-income countries with similar health infrastructures.

Acknowledgements: We thank the Bangladesh Demographic and Health Surveys Programme for allowing us to use the data.

Source of support: None.

Conflict of interest: None declared.

Authorship: TA processed and analysed the data and drafted the paper. AD supervised and contributed to drafting the paper. DS supervised and contributed to the data analysis and drafting the paper. All the authors contributed to the study conception and approved the final version to be published.

How to cite this paper: Akter T, Dawson A, Sibbritt D. Changes in neonatal mortality and newborn health-care practices: descriptive data from the Bangladesh Demographic and Health Surveys 2011 and 2014. WHO South-East Asia J Public Health. 2018;7(1)

\section{References}

1. Chowdhury AMR, Bhuiya A, Chowdhury ME, Rasheed S, Hussain Z, Chen LC. The Bangladesh paradox: exceptional health achievement despite economic poverty. Lancet.

2013;382(9906):1734-45. doi:10.1016/S0140-6736(13)62148-0.

2. Bangladesh Demographic and Health Survey 2014. Dhaka and Rockville: National Institute of Population Research and Training (NIPORT), Mitra and Associates and ICF International; 2016 (https://dhsprogram.com/pubs/pdf/FR311/FR311.pdf, accessed 23 January 2018).

3. El Arifeen S, Christou A, Reichenbach L, Osman FA, Azad K, Islam KS et al. Community-based approaches and partnerships: innovations in health-service delivery in Bangladesh. Lancet. 2013;382(9909):2012-26. doi:10.1016/S0140-6736(13)62149-2.

4. Mitra SN, Al-Sabir A, Cross AR, Jamil K. Bangladesh Demographic and Health Survey, 19961997. Dhaka and Calverton: National Institute of Population Research and Training (NIPORT), Mitra and Associates and Macro International; 1997 (https://dhsprogram.com/pubs/pdf/FR88/FR88.pdf, accessed 23 January 2018).

5. Baqui AH, Arifeen SE, Darmstadt GL, Ahmed S, Williams EK, Seraji HR et al. Effect of communitybased newborn-care intervention package implemented through two service-delivery strategies 
in Sylhet district, Bangladesh: a cluster-randomised controlled trial. Lancet.

2008;371(9628):1936-44. doi:10.1016/S0140-6736(08)60835-1.

6. Bangladesh health system review. Geneva: World Health Organization; 2015 (http://iris.wpro.who.int/handle/10665.1/11357, accessed 23 January 2018).

7. Bangladesh Maternal Mortality and Health Care Survey 2016: preliminary report. Dhaka, Bangladesh, Chapel Hill: National Institute of Population Research and Training (NIPORT), International Centre for Diarrhoeal Disease Research, Bangladesh (icddrb) and MEASURE Evaluation; 2017 (https://www.measureevaluation.org/resources/publications/tr-17-218, accessed 23 January 2018).

8. Working together for health. The World Health Report 2006. Geneva: World Health Organization; 2006 (http://www.who.int/whr/2006/whr06 en.pdf?ua=1, accessed 23 January 2018).

9. Ahmed SM, Hossain MA, RajaChowdhury AM, Bhuiya AU. The health workforce crisis in Bangladesh: shortage, inappropriate skill-mix and inequitable distribution. Hum Resour Health. 2011; 9:1-7. doi:10.1186/1478-4491-9-3.

10. United Nations. Sustainable development goals: 17 goals to transform our world (http://www.un.org/sustainabledevelopment/sustainable-development-goals/, accessed 23 January 2018).

11. Bangladesh Demographic and Health Survey 2011. Dhaka, Bangladesh and Calverton: National Institute of Population Research and Training (NIPORT), Mitra and Associates and ICF International; 2013 (https://dhsprogram.com/pubs/pdf/fr265/fr265.pdf, accessed 23 January 2018).

12. The DHS Program: Demographic and Health Surveys. Protecting the privacy of DHS survey respondents (https://dhsprogram.com/What-We-Do/Protecting-the-Privacy-of-DHS-SurveyRespondents.cfm, accessed 23 January 2018).

13. Essential interventions, commodities and guidelines for reproductive, maternal, newborn and child health. A global review of the key interventions related to reproductive, maternal, newborn and child health (RMNCH). Geneva: The Partnership for Maternal Newborn and Child Health; 2011 (http://apps.who.int/medicinedocs/documents/s21666en/s21666en.pdf, accessed 23 January 2018).

14. Rutstein S. Infant and child mortality: levels, trends and demographic differentials. Revised edition (WFS Comparative Studies No. 43; Cross National Summaries). Voorburg: International Statistical Institute; 1984.

15. National Neonatal Health Strategy and Guidelines for Bangladesh. Dhaka: Ministry of Health and Family Welfare, Government of the People's Republic of Bangladesh; 2009 (https://extranet.who.int/nutrition/gina/sites/default/files/BGD\%202009\%20National\%20Neon atal\%20Health\%20Strategy.pdf, accessed 23 January 2018).

16. WHO/UNICEF joint statement. Home visits for the newborn child: a strategy to improve survival. Geneva: World Health Organization; 
2009(http://apps.who.int/iris/bitstream/10665/70002/1/WHO FCH CAH 09.02 eng.pdf, accessed 23 January 2018).

17. Akter T, Dawson A, Sibbritt D. What impact do essential newborn care practices have on neonatal mortality in low and lower-middle income countries? Evidence from Bangladesh. J Perinatol. 2015;36(3):225-30. doi:10.1038/jp.2015.181.

18. Akter T, Dawson A, Sibbritt D. The determinants of essential newborn care for homebirths in Bangladesh. Public Health. 2016;141:7-16. doi:10.1016/j.puhe.2016.08.004.

19. Rutstein S. Wealth versus expenditure: comparison between the DHS wealth index and household expenditures in four departments of Guatemala. Calverton: ORC Macro; 1999.

20. Perz SG. Population change. In: Siegel JS, Swanson DA, editors. The methods and materials of demography, 2nd ed. San Diego: Elsevier Academic Press; 2004:253-64.

21. Report of the household income and expenditure survey 2010.Dhaka: Bangladesh Bureau of Statistics, Ministry of Planning, Government of the People's Republic of Bangladesh; 2010 (http://www.washingtongroup-disability.com/wp-content/uploads/2016/03/2010- HouseholdIncome-and-Expenditure-Survey-HIES.pdf, accessed 23 January 2018).

22. Bryan G, Chowdhury S, Mobarak AM. Underinvestment in a profitable technology: the case of seasonal migration in Bangladesh. Econometrica. 2014;82(5):1671-748.

doi:10.3982/ECTA10489.

23. Kiros G-E, Hogan DP. War, famine and excess child mortality in Africa: the role of parental education. Int J Epidemiol. 2001;30(3):447-55. doi:10.1093/ije/30.3.447.

24. Lawn JE, Cousens S, Zupan J. 4 million neonatal deaths: when? Where? Why? Lancet. 2005;365(9462):891-900. doi:10.1016/S0140-6736(05)71048-5.

25. Haque U, Hashizume M, Kolivras KN, Overgaard HJ, Das B, Yamamoto T. Reduced death rates from cyclones in Bangladesh: what more needs to be done? Bull World Health Organ. 2012;90(2):150-6. doi:10.2471/BLT.11.088302.

26. Seventh Five Year Plan. FY2016-FY2020. Accelerating growth, empowering citizens. Dhaka: General Economics Division (GED), Planning Commission, Government of the People's Republic of Bangladesh; 2015 (http://www.plancomm.gov.bd/wp-content/uploads/2015/11/7FYP afterNEC 1111 2015.pdf, accessed 23 January 2018).

27. A strategy for poverty reduction in the lagging regions of Bangladesh. Dhaka: General Economics Division, Planning Commission, Government of the People's Republic of Bangladesh; 2008 (https://www.scribd.com/document/142070382/A-Strategy-for-Poverty-Reduction-inTheLagging-Regions-of-Bangladesh, accessed 23 January 2018).

28. Datar A, Liu J, Linnemayr S, Stecher $C$. The impact of natural disasters on child health and investments in rural India. Soc Sci Med. 2013;76(1):83-91. doi:10.1016/j.socscimed.2012.10.008.

29. Baqui AH, Ahmed S, Arifeen SE, Darmstadt GL, Rosecrans AM, Mannan I et al. Effect of timing of first postnatal care home visit on neonatal mortality in Bangladesh: a observational cohort study. BMJ. 2009;339:b2826. doi:10.1136/bmj.b2826. 
30. El Arifeen S. Child health and mortality. J Health Popul Nutr. 2008;26(3):273-9.

31. Health, Population and Nutrition Sector Development Program (2011-2016). Program Implementation Plan (PIP). Volume 1.Dhaka: Ministry of Health and Family Welfare, Government of the People's Republic of Bangladesh; 2011

(http://www.nationalplanningcycles.org/sites/default/files/country docs/Bangladesh/banglade sh hpnsdp 2011-2016.pdf, accessed 23 January 2018).

32. Titaley CR, Dibley MJ, Roberts CL. Factors associated with underutilization of antenatal care services in Indonesia: results of Indonesia Demographic and Health Survey 2002/2003 and 2007. BMC Public Health. 2010;10:485. doi:10.1186/1471-2458-10-485.

33. Prost A, Colbourn T, Seward N, Azad K, Coomarasamy A, Copas A et al. Women's groups practising participatory learning and action to improve maternal and newborn health in lowresource settings: a systematic review and meta-analysis. Lancet. 2013;381(9879):1736-46. doi:10.1016/S0140-6736(13)60685-6.

34. Barcellos SH, Carvalho LS, Lleras-Muney A. Child gender and parental investments in India: are boys and girls treated differently? Am Econ J:Appl Econ. 2014;6(1):157-89. doi:10.1257/app.6.1.157.

35. Akter $T$, Sibbritt $D$, Dawson $A$. Workforce interventions to deliver postnatal care to improve neonatal outcomes in low-and lower-middle-income countries: a narrative synthesis. Asia Pac J Public Health. 2016;28(8):659-81. doi:10.1177/1010539516656435.

36. Health Bulletin 2015. Dhaka: Ministry of Health and Family Welfare, Government of the People's Republic of Bangladesh; 2015 (http://www.dghs.gov.bd/images/docs/Publicaations/HB\%202015 1st edition 31122015.pdf, accessed 23 January 2018). 
Table 1. Neonatal mortality rates by demographic and socioeconomic characteristics in the Bangladesh Demographic and Health Surveys 2011 and 2014 2,11

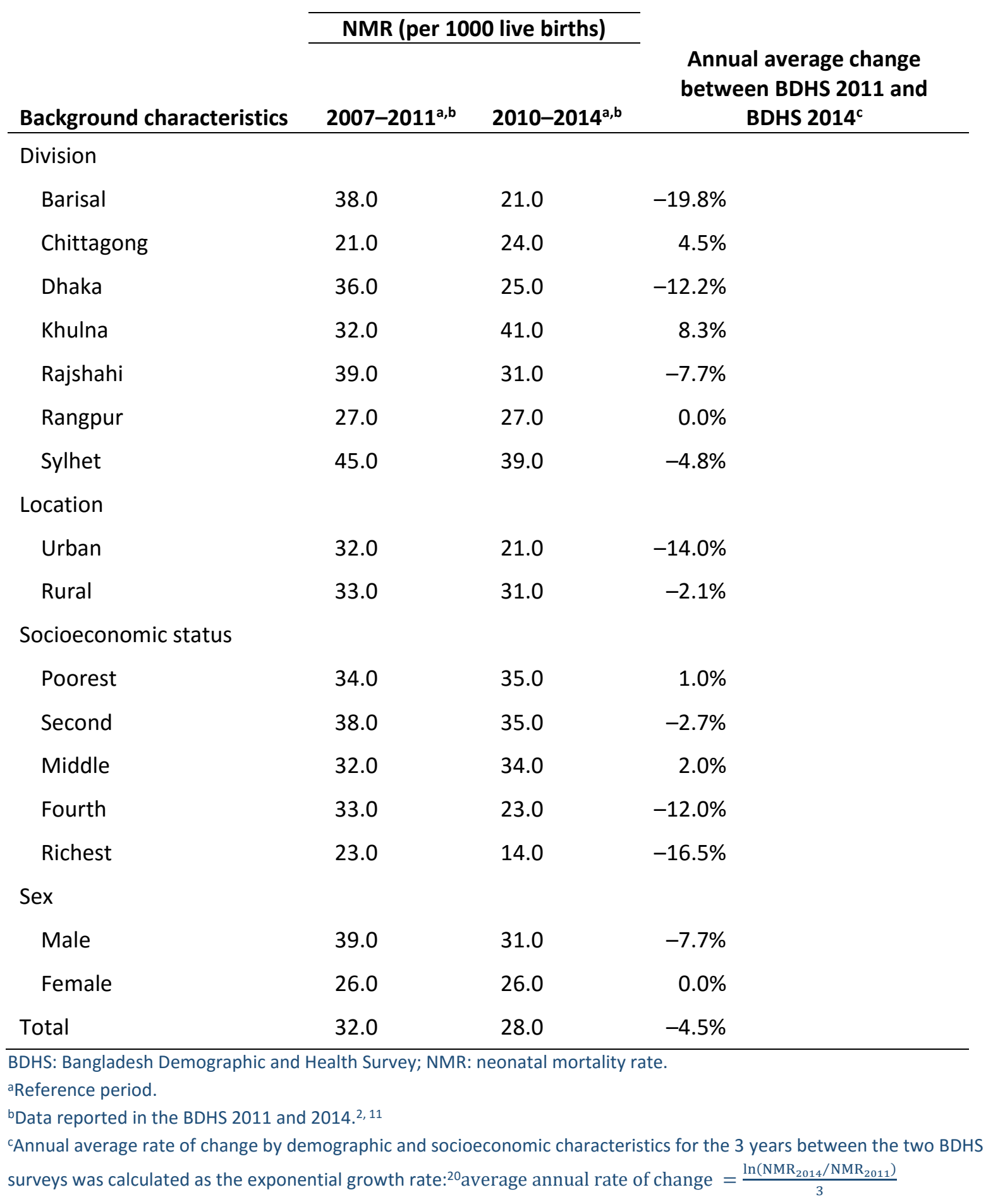


Table 2.Neonatal health-care practices (\%) in the Bangladesh Demographic and Health Surveys 2011 and 2014, by administrative division ${ }^{2,11}$ 


\begin{tabular}{|c|c|c|c|c|c|c|c|c|c|c|c|c|c|c|}
\hline \multirow{3}{*}{$\begin{array}{l}\text { Health- } \\
\text { care } \\
\text { practice }\end{array}$} & \multicolumn{14}{|c|}{ Divisions } \\
\hline & \multicolumn{2}{|c|}{ Barisal } & \multicolumn{2}{|c|}{ Chittagong } & \multicolumn{2}{|c|}{ Dhaka } & \multicolumn{2}{|c|}{ Khulna } & \multicolumn{2}{|c|}{ Rajshahi } & \multicolumn{2}{|c|}{ Rangpur } & \multicolumn{2}{|c|}{ Sylhet } \\
\hline & $\begin{array}{c}2011 n= \\
260\end{array}$ & $\begin{array}{c}2014 n= \\
268\end{array}$ & $\begin{array}{c}2011 n=1 \\
083\end{array}$ & $\begin{array}{c}2014 n=1 \\
011\end{array}$ & $\begin{array}{c}2011 n=1 \\
418\end{array}$ & $\begin{array}{c}2014 n=1 \\
634\end{array}$ & $\begin{array}{c}2011 n= \\
441\end{array}$ & $\begin{array}{c}2014 n= \\
371\end{array}$ & $\begin{array}{c}2011 n= \\
618\end{array}$ & $\begin{array}{c}2014 n= \\
464\end{array}$ & $\begin{array}{c}2011 n= \\
491\end{array}$ & $\begin{array}{c}2014 n= \\
450\end{array}$ & $\begin{array}{c}2011 n= \\
342\end{array}$ & $\begin{array}{c}2014 n= \\
428\end{array}$ \\
\hline $\begin{array}{l}\text { Received } \\
\text { at least } 4 \\
\text { antenatal } \\
\text { care visits }\end{array}$ & 27.0 & 24.6 & 20.3 & 25.5 & 26.6 & 35.5 & 33.3 & 38.8 & 21.4 & 26.5 & 38.4 & 41.3 & 15.9 & 19.8 \\
\hline $\begin{array}{l}\text { Delivered } \\
\text { in a } \\
\text { health } \\
\text { facility }\end{array}$ & 22.3 & 29.9 & 24.8 & 35.2 & 29.9 & 40.5 & 45.8 & 54.6 & 29.8 & 39.2 & 27.6 & 34.3 & 21.0 & 22.6 \\
\hline $\begin{array}{l}\text { Assisted } \\
\text { by a } \\
\text { medically } \\
\text { trained } \\
\text { provider } \\
\text { during } \\
\text { delivery }\end{array}$ & 28.4 & 36.7 & 29.7 & 43.9 & 31.5 & 43.5 & 49.0 & 58.2 & 30.9 & 41.6 & 28.7 & 37.9 & 24.4 & 27.1 \\
\hline $\begin{array}{l}\text { Used } \\
\text { sterile/bo } \\
\text { iled } \\
\text { instrume } \\
\text { nts for } \\
\text { cutting } \\
\text { the } \\
\text { umbilical } \\
\text { cord }^{\text {a }}\end{array}$ & 80.0 & 78.5 & 84.9 & 85.6 & 82.1 & 83.1 & 84.2 & 88.9 & 78.7 & 69.6 & 88.0 & 84.6 & 89.8 & 87.9 \\
\hline $\begin{array}{l}\text { Dried } \\
\text { within 0- } \\
4 \text { min } \\
\text { after } \\
\text { birth }^{\text {a }}\end{array}$ & 47.7 & 56.2 & 51.9 & 65.6 & 52.0 & 63.7 & 50.3 & 71.7 & 57.8 & 74.6 & 49.4 & 73.9 & 44.1 & 70.3 \\
\hline $\begin{array}{l}\text { Delayed } \\
\text { bathing } \\
\text { (>72 h } \\
\text { after } \\
\text { delivery) }{ }^{a}\end{array}$ & 37.3 & 33.2 & 23.3 & 28.2 & 23.6 & 33.8 & 24.0 & 31.1 & 31.2 & 35.9 & 47.6 & 50.7 & 28.3 & 34.6 \\
\hline
\end{tabular}




\begin{tabular}{|c|c|c|c|c|c|c|c|c|c|c|c|c|c|c|}
\hline $\begin{array}{l}\text { Breastfee } \\
\text { ding } \\
\text { (within } \\
1 \text { h after } \\
\text { birth) }\end{array}$ & 46.9 & 56.4 & 50.3 & 50.1 & 45.5 & 58.0 & 50.2 & 52.2 & 53.7 & 63.0 & 51.6 & 64.3 & 57.3 & 60.3 \\
\hline $\begin{array}{l}\text { Postnatal } \\
\text { care } \\
\text { within } \\
2 \text { days } \\
\text { after } \\
\text { birth } \\
\text { from a } \\
\text { trained } \\
\text { provider }\end{array}$ & 26.3 & 30.6 & 26.0 & 33.0 & 31.5 & 30.5 & 46.6 & 41.6 & 27.0 & 36.2 & 26.9 & 29.4 & 22.6 & 20.7 \\
\hline
\end{tabular}


Table 3. Neonatal health-care practices (\%) in the Bangladesh Demographic and Health Surveys 2011 and 2014, by urban/rural location ${ }^{2,11}$

\begin{tabular}{|c|c|c|c|c|}
\hline \multirow[b]{3}{*}{ Health-care practice } & \multicolumn{4}{|c|}{ Location } \\
\hline & \multicolumn{2}{|c|}{ Urban } & \multicolumn{2}{|c|}{ Rural } \\
\hline & $2011 n=1068$ & $2014 n=1209$ & $2011 n=3584$ & $2014 n=3418$ \\
\hline Received at least 4 antenatal care visits & 44.7 & 45.5 & 19.8 & 26.1 \\
\hline Delivered in a health facility & 49.3 & 56.8 & 22.8 & 30.6 \\
\hline $\begin{array}{l}\text { Assisted by a medically trained provider } \\
\text { during delivery }\end{array}$ & 53.7 & 60.5 & 25.2 & 35.6 \\
\hline $\begin{array}{l}\text { Used sterile/boiled instruments for } \\
\text { cutting the umbilical cord }{ }^{a}\end{array}$ & 87.8 & 84.9 & 82.8 & 82.7 \\
\hline Dried within 0-4 min after birth ${ }^{a}$ & 50.6 & 68.1 & 51.6 & 66.7 \\
\hline Delayed bathing (>72 $\mathrm{h}$ after delivery) ${ }^{\mathrm{a}}$ & 28.5 & 30.0 & 28.4 & 35.3 \\
\hline Breastfeeding (within $1 \mathrm{~h}$ after birth) ${ }^{\mathrm{a}}$ & 51.6 & 54.7 & 49.4 & 57.7 \\
\hline $\begin{array}{l}\text { Postnatal care within } 2 \text { days after birth } \\
\text { from a trained provider }\end{array}$ & 50.3 & 50.9 & 23.4 & 24.6 \\
\hline
\end{tabular}


Table 4.Neonatal health-care health practices (\%) in the Bangladesh Demographic and Health Surveys 2011 and 2014, by socioeconomic status ${ }^{2,11}$

\begin{tabular}{|c|c|c|c|c|c|c|c|c|c|c|}
\hline \multirow[b]{3}{*}{$\begin{array}{l}\text { Health-care } \\
\text { practice }\end{array}$} & \multicolumn{10}{|c|}{ Socioeconomic status } \\
\hline & \multicolumn{2}{|c|}{ Poorest } & \multicolumn{2}{|c|}{ Second } & \multicolumn{2}{|c|}{ Middle } & \multicolumn{2}{|c|}{ Fourth } & \multicolumn{2}{|c|}{ Richest } \\
\hline & $\begin{array}{c}2011 n=106 \\
2\end{array}$ & $\begin{array}{c}2014 n=100 \\
3\end{array}$ & $\begin{array}{c}2011 n=92 \\
0\end{array}$ & $\begin{array}{c}2014 n=87 \\
6\end{array}$ & $\begin{array}{c}2011 n=91 \\
9\end{array}$ & $\begin{array}{c}2014 n=88 \\
2\end{array}$ & $\begin{array}{c}2011 n=91 \\
1\end{array}$ & $\begin{array}{c}2014 n=95 \\
5\end{array}$ & $\begin{array}{c}2011 n=84 \\
1\end{array}$ & $\begin{array}{c}2014 n=91 \\
2\end{array}$ \\
\hline $\begin{array}{l}\text { Received at } \\
\text { least } 4 \\
\text { antenatal } \\
\text { care visits }\end{array}$ & 10.6 & 15.4 & 14.9 & 20.0 & 21.0 & 27.2 & 32.7 & 38.7 & 53.2 & 55.1 \\
\hline $\begin{array}{l}\text { Delivered in } \\
\text { a health } \\
\text { facility }\end{array}$ & 9.9 & 14.9 & 17.5 & 24.1 & 24.1 & 34.0 & 39.4 & 46.3 & 59.8 & 70.2 \\
\hline $\begin{array}{l}\text { Assisted by a } \\
\text { medically } \\
\text { trained } \\
\text { provider } \\
\text { during } \\
\text { delivery }\end{array}$ & 11.5 & 17.9 & 18.6 & 29.9 & 28.2 & 38.8 & 43.2 & 52.0 & 63.8 & 74.4 \\
\hline $\begin{array}{l}\text { Used } \\
\text { sterile/boiled } \\
\text { instruments } \\
\text { for cutting } \\
\text { the umbilical } \\
\text { cord }^{\mathrm{a}}\end{array}$ & 81.4 & 81.4 & 81.8 & 83.5 & 83.9 & 81.8 & 86.7 & 86.2 & 88.6 & 84.6 \\
\hline $\begin{array}{l}\text { Dried within } \\
0-4 \text { min after } \\
\text { birth }\end{array}$ & 48.4 & 66.3 & 51.8 & 65.4 & 54.1 & 61.3 & 49.4 & 72.5 & 56.9 & 75.1 \\
\hline $\begin{array}{l}\text { Delayed } \\
\text { bathing } \\
\text { (>72 h after } \\
\text { delivery })^{\mathrm{a}}\end{array}$ & 26.3 & 28.7 & 28.6 & 35.7 & 26.3 & 38.9 & 33.2 & 37.0 & 30.0 & 34.4 \\
\hline $\begin{array}{l}\text { Breastfeedin } \\
\mathrm{g}(\text { within } 1 \mathrm{~h} \\
\text { after birth) }\end{array}$ & 47.5 & 60.8 & 47.8 & 53.0 & 54.1 & 55.2 & 52.1 & 59.4 & 48.6 & 56.0 \\
\hline
\end{tabular}


2 days after

birth from a

trained

provider

asample excludes facility birth. 
Table 5. Neonatal health-care practices in the Bangladesh Demographic and Health Surveys 2011 and 2014, by sex ${ }^{2,11}$

\begin{tabular}{|c|c|c|c|c|}
\hline \multirow[b]{3}{*}{ Health-care practice } & \multicolumn{4}{|c|}{ Sex } \\
\hline & \multicolumn{2}{|c|}{ Male } & \multicolumn{2}{|c|}{ Female } \\
\hline & $2011 n=2352$ & $2014 n=2439$ & $2011 n=2300$ & $2014 n=2188$ \\
\hline Received at least 4 antenatal care visits & 26.5 & 32.1 & 24.5 & 30.2 \\
\hline Delivered in a health facility & 29.1 & 39.1 & 28.6 & 35.9 \\
\hline $\begin{array}{l}\text { Assisted by a medically trained provider } \\
\text { during delivery }\end{array}$ & 32.2 & 43.7 & 31.1 & 40.2 \\
\hline $\begin{array}{l}\text { Used sterile/boiled instruments for } \\
\text { cutting the umbilical cord }\end{array}$ & 83.5 & 82.2 & 83.8 & 84.0 \\
\hline Dried within 0-4 min after birth ${ }^{\mathrm{a}}$ & 51.4 & 66.3 & 51.4 & 67.7 \\
\hline Delayed bathing (>72 $\mathrm{h}$ after delivery) ${ }^{\mathrm{a}}$ & 28.9 & 38.2 & 27.8 & 30.3 \\
\hline Breastfeeding (within $1 \mathrm{~h}$ after birth) ${ }^{\mathrm{a}}$ & 50.8 & 56.3 & 48.8 & 58.1 \\
\hline $\begin{array}{l}\text { Postnatal care within } 2 \text { days after birth } \\
\text { from a trained provider }\end{array}$ & 30.4 & 32.1 & 28.8 & 30.8 \\
\hline
\end{tabular}

